\title{
Autoimmune Thyroid Disease and Refractory Chronic Urticaria: Thyroidectomy as a Treatment for Long Standing Remission. A Case Report
}

\author{
One Sentence Summary: A 36-year-old woman with a refractory chronic \\ autoimmune urticaria and a concomitant autoimmune thyroid disease achieved \\ remission from the dermatological point of view after thyroidectomy.
}

\author{
Authors \\ C. Francés ${ }^{1}$, J. Nicolau ${ }^{1}$, M. García ${ }^{2}$, C. Nadal ${ }^{3}$, L. A. Gómez ${ }^{1}$, L. Masmiquel \\ Affiliations \\ 1 Endocrinology and Nutrition Department \\ 2 Pathological Anatomy Department \\ ${ }^{3}$ Dermatology Department, Hospital Son Llàtzer, Palma de Mallorca, Spain
}

Key words

- autoimmune thyroid disease

- chronic urticaria

- thyroidectomy

- thyroid antibodies

\section{Abstract}

$\nabla$

The relationship between autoimmune thyroid disease and chronic autoimmune urticaria has been well established, even though the cause is still unknown. Several medical treatments have been proposed for chronic autoimmune urticaria, being antihistamines the first line. However, not all of the cases respond to this therapy, and other alternatives have been suggested, including corticosteroids, leukotriene antagonists or immunosuppressive drugs. Clinical improvement has also been reported after performing a thyroidectomy in 9 patients.

\section{Introduction}

received 13.07.2014

first decision 13.07.2014

accepted $\quad 18.08 .2014$

Bibliography

DOI http://dx.doi.org/

10.1055/s-0034-1389902

Published online:

October 14, 2014

Exp Clin Endocrinol Diabetes

Rep 2014; 1: e4-e7

(C) J. A. Barth Verlag in

Georg Thieme Verlag KG

Stuttgart · New York

ISSN 2196-7407

\section{Correspondence}

Carla Francés

Hospital Son Llàtzer

Carretera de Manacor Km 4

Palma de Mallorca

Spain

07918

Tel.: + 34/871/202 055

Fax: +34/871/202 232

cfrancesartigas@gmail.com

\section{License terms}

$(\Theta(1) \Theta \Theta$ $\nabla$

The relationship between autoimmune thyroid disease (AITD) and chronic autoimmune urticaria (CAU) was first described in the decade of the 1980s [1-4]. Since then, multiple cases have been reported, but its pathogenic mechanisms are not well known. CAU is a distressing disease defined as the presence of recurrent, transient and itching maculo-papular skin lesions with or without angioedema, that last more than 6 weeks [5]. Diagnose is confirmed with an autologous serum skin test, which is considered positive if a papule bigger than $16 \mathrm{~mm}$ is obtained [5]. First-line treatment has been based on the use of nonsedating, second-generation antihistamines; following the recommendations of the recent international guidelines, in patients who do not respond to antihistamines at licensed doses, the daily dosage of these drugs can be increased up to 4-fold [6]. However, a significant proportion of patients with chronic urticaria remain poorly controlled; in these cases, alternative therapeutic approaches have to be considered. Nonetheless, even then, a percentage of cases remain symptomatic. We report a case of AITD and
We present the case of a 36-year-old woman who developed a chronic autoimmune urticaria that did not respond to conservative treatment. During the initial study, she was diagnosed with a euthyroid autoimmune disease, that evolved into a subclinical hyperthyroidism 2 months later. Even though thyroid function was restored with anti-thyroid drugs, urticaria persisted, and finally it was decided to perform a thyroidectomy. After surgery, the patient stayed asymptomatic from the dermatological point of view, with no relapses more than 2 years later. Therefore, thyroidectomy is proposed as a new therapeutical option in patients with refractory chronic autoimmune urticaria.

refractory CAU with complete and long-standing remission after thyroidectomy. Furthermore, we examine the medical literature for evidences supporting thyroidectomy as a treatment for refractory CAU in patients with thyroid disease.

\section{Case Report \\ $\nabla$}

A 36-year-old woman was referred to a dermatology clinic due to pruritic skin lesions. She had no allergies or toxic habits. Her personal clinical history was unremarkable except for 3 episodes of paroxysmal supraventricular tachycardia, which resolved after electric ablation in 2002.

The patient started having recurrent maculopapular lesions which were compatible with urticaria in February 2009. During physical examination, a grade 1 goiter without nodules or palpable adenopathies was found.

A pharmacologic, infectious or atopic aetiology was ruled out, and allergy tests were conducted, obtaining negative results. Alfa trypsin and complement factors were normal. Autoantibodies were also determined to discard connective tissue diseases. All the titres were undetectable 
except for thyroid antibodies (anti-thyroid microsomal haemagglutination antibodies (MGHA): $746 \mathrm{U} / \mathrm{ml}$ (NR 0-60U/ml); antithyroglobulin haemagglutination antibodies (TGHA): $10 \mathrm{U} / \mathrm{ml}$ (NR $0-60 \mathrm{U} / \mathrm{ml})$ ). TSH was normal $(0.9 \mathrm{mcU} / \mathrm{ml}$, NR $0.55-$ $4.78 \mathrm{mcU} / \mathrm{ml}$ ).

A cutaneous biopsy showed perivascular oedema with a lymphocitary infiltrate, compatible with urticaria $(\bullet$ Fig. 1$)$. A positive autologous serum skin test was obtained, and the patient was diagnosed with $\mathrm{CAU}$, starting therapy with dexclorpheniramine $2 \mathrm{mg}$ every $8 \mathrm{~h}$.

2 months later, subclinical hyperthyroidism was detected, with TSH $0.180 \mathrm{mcU} / \mathrm{ml}$ (NR: $0.55-4.78 \mathrm{mcU} / \mathrm{ml}$ ), free T4 $1.06 \mathrm{ng} / \mathrm{dl}$ (NR: $0.89-1.76 \mathrm{ng} / \mathrm{dl}$ ) and free T3 $2.62 \mathrm{pg} / \mathrm{ml}$ (NR: $2.3-4.2 \mathrm{pg} / \mathrm{ml}$ ). The titre of TSH-R antibodies was 7U/L (NR: 0-10U/L). A gammagraphy was carried out, showing a diffuse moderate hypercaptating goiter, and ultrasonography reported an enlargement of the superior part of the right lobe $(55 \times 17 \times 19 \mathrm{~mm})$, being the left one of normal size $(40 \times 16 \times 18 \mathrm{~mm})$, without echogenicity alterations, focal lesions or adenopathies. At this point, carbimazole $5 \mathrm{mg}$ per day was started.

Due to the persistence of the urticaria at that moment, $5 \mathrm{mg}$ of prednisone per day were added. Euthyroidism was achieved with carbimazole and lasted 6 months. Afterwards, the patient's thyroid function worsened with TSH $0.007 \mathrm{mcU} / \mathrm{mL}$, free T3 $15.86 \mathrm{pg} / \mathrm{ml}$ and free T4 $3.84 \mathrm{ng} / \mathrm{dl}$. Treatment with metimazole $15 \mathrm{mg}$ per day was undertaken, obtaining normalization of thyroid function tests 8 weeks later. Subsequently, anti-thyroid drugs were withdrawn. However, during this period, the urticaria worsened progressively, and treatment with desloratadine $5 \mathrm{mg}$ and deflazacort $6 \mathrm{mg}$ during alternate days was tried out, without clinical remission.

6 months later, the patient had a normal thyroid function with persistence of positive thyroid antibodies. Due to the unresponsiveness of CAU, it was decided to perform a total thyroidectomy, and histological examination showed a diffuse hyperplasia in the context of a chronic lymphocitary thyroiditis ( $\bullet$ Fig. 2). After surgery, treatment with levothyroxine $75 \mathrm{mcg}$ per day was started. Remarkably, urticaria resolved immediately after the thyroidectomy, and the patient remained euthyroid and totally asymptomatic more than 2 years later. At this point, thyroid autoantibodies were negative (last observation: January 16, 2014).

\section{Discussion}

\section{$\nabla$}

A relationship between CAU and AITD has been consistently reported since 1983. In this regard, several studies have shown higher prevalence and titres of thyroid autoantibodies among patients with CAU [5,7-12]. The greatest study published so far analysing the relationship between CAU and autoimmune disorders, compared 12778 patients with 10714 controls, and thyroid diseases were established as the most common autoimmune disorder in patients with CAU. Hypothyroidism was diagnosed in $9.8 \%$ of cases, in comparison to $0.6 \%$ of controls ( $p<0.0005$ ), and hyperthyroidism in $2.6 \%$ vs. $0.09 \%(\mathrm{p}<0.0005)$. MGHA were identified in $4.7 \%$ of cases in the patient group vs. $0.4 \%$ of the control group ( $\mathrm{p}<0.0005)$, and $1 \%$ had TGHA in comparison to $0.04 \%$ of controls $(p<0.0005)[12$ ]. In the same way, O'Donell et al. suggested that the risk for positive MGHA and abnormal thyroid function is 4 and 15 times higher, respectively, among patients with a positive skin test [9]. Interestingly, 6 cases of papillary thyroid carcinoma (PTC) have also been reported in patients with CAU [13-15]. However, thyroid autoimmunity was positive only in one of them. Nevertheless, the fact that thyroidectomy achieved remission in these patients could suggest that other unknown antibodies directed towards thyroid tissue are responsible for the relationship between PTC and CAU.

The autoimmune mechanism by which urticaria is produced is mediated by the humoral immune system. In $30-40 \%$ of cases, IgG auto-antibodies against the alpha chain of the high affinity Fc receptor for IgE (FceRI $\alpha$ ) have been described [16-18], and in $50 \%$ of them, IgG directed towards IgE [19]. These antibodies activate basophils and mast cells to release histamine, and complement fixation augments histamine release by formation of C5a anaphylatoxin [20].

On the other hand, autoimmune thyroiditis is produced due to the action of cellular immunity. In this case, there is a functional defect of suppressor cells and an activation of autoreactive $T$ cells, which cooperate with B cells to stimulate the production of anti-thyroidal antibodies [5]. However, MGHA and TGHA-mediated complement activation has been observed in some studies, and some authors have speculated that different autoantigen-

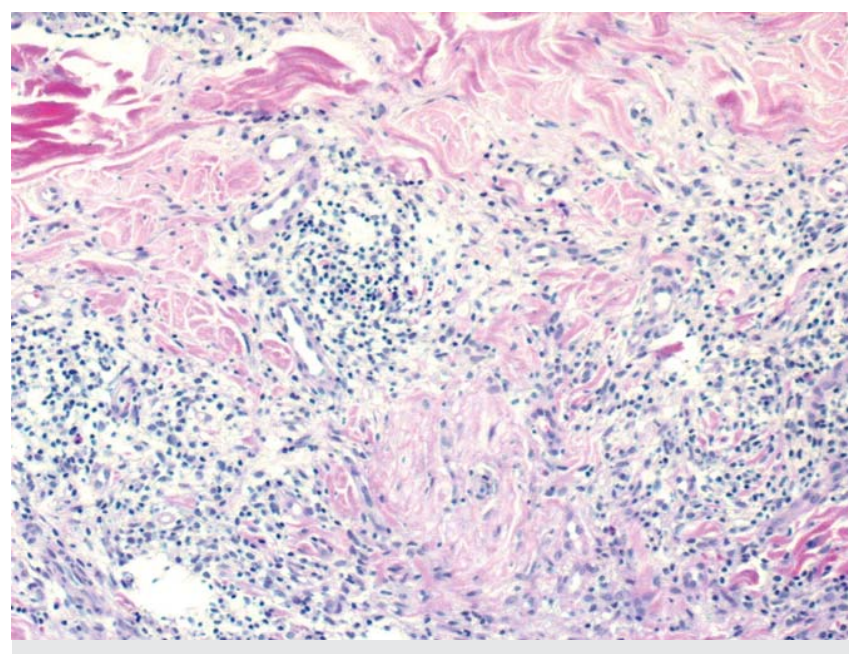

Fig. 1 Urticaria skin histology (hematoxylin-eosin stain, $100 \times$ magnification). An interstitial oedema with a perivascular lymphocitary and polymorphonuclear infiltrate can be observed.

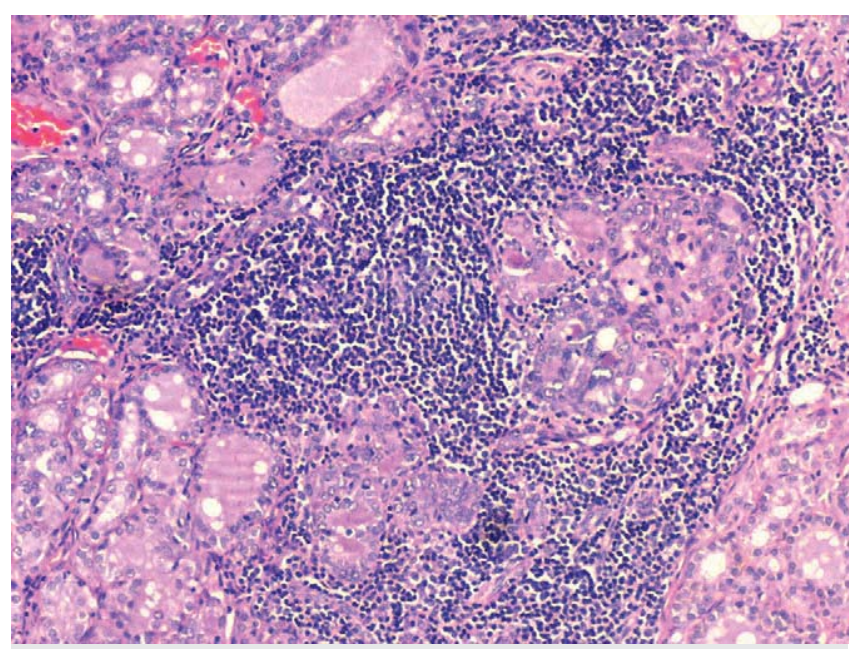

Fig. 2 Thyroid histology (hematoxylin-eosin stain, $40 \times$ magnification) showing a diffuse hyperplasia in the context of a chronic lymphocitary thyroiditis. 
autoantibody systems (anti-FceRI $\alpha$, MGHA) synergize in generating $\mathrm{C} 5 \mathrm{a}$ and triggering mast cells and basophils in patients with Hashimoto thyroiditis [21]. As well as this, the cytotoxic T-lymphocyte associated antigen 4 (CTLA4) gene has been shown to be a susceptibility factor for Hashimoto's thyroiditis and Grave's disease, and Brzoza et al. hypothesized that it could also have a role in CAU [22]. Furthermore, recently Ramos-Prol et al. have suggested CAU as a possible non-endocrine manifestation of autoimmune polyglandular syndrome type II [23]. However, another hypothesis is that some infectious agents could be involved in the pathogenesis of both chronic urticaria and thyroiditis. Thus, several clinical and experimental observations suggest a relationship between agents like hepatitis $\mathrm{C}$ virus, Staphylococcus aureus and Helicobacter pylori with both CAU and AITD [24-27].

It therefore seems logical to state that thyroid examination together with thyroid function tests and autoantibodies titration is advisable in CAU patients.

It is generally accepted that CAU patients should undergo a stepwise treatment, considering that in most cases stepping-up implies an increase in both costs and adverse effects. This process considers leukotriene receptors antagonists or short courses of steroids after high doses of second generation $\mathrm{H} 1$ antihistamines. If the disease relapses or persists, needing permanent corticosteroid treatment, the next option should be cyclosporine. Even omalizumab, a monoclonal IgG antibody that binds free $\operatorname{IgE}$ and downregulates mast cell function, can be considered [6]. However, nowadays the evidence supporting the use of other immunosuppressive agents, anti-inflammatory drugs, anticoagulants and intravenous immunoglobulins is scarce and insufficient to recommend their routine use.

We report a case of refractory CAU associated to AITD that resolved immediately after thyroidectomy. The patient was first treated with antihistamines and afterwards with corticosteroids, with no response. However, only a second generation antihistamine (desloratadine) was used, and it cannot be excluded that $30 \mathrm{mg} /$ day of cetirizine would have gained a better clinical result. In any case, after observing that the patient had not improved with initial medical treatment, several options were considered. It must be kept in mind that, although heavily disturbing and long-lasting, refractory CAU is not a life-threatening disease and does not imply a risk for organ failure. Therefore, the aim of the treatment should be to control the disease with the least possible adverse effects. It is well known that numerous toxicities, mainly the development of iatrogenic Cushing's syndrome and inhibition of hypothalamic-pituitary-adrenal func- tion, are related to glucocorticoids. These effects are more common in patients receiving high doses over a long period of time. In this regard, our patient was being treated with $6 \mathrm{mg}$ of deflazacort during alternate days, without response. Thus, the next logical pharmacological option would have been to start omalizumab or a calcineurin inhibitor such as cyclosporine and tacrolimus [6], which are used for approximately 3-6 months. However, in some cases, CAU relapses after drug discontinuation, and long term maintenance therapy has been suggested if this occurs. Important side effects, mainly nephrotoxicity, hypertension, neurotoxicity, metabolic abnormalities and increased risk of malignancy have been reported for both drugs. Therefore, during treatment, blood pressure and kidney and liver function tests must be assessed regularly. Finally, omalizumab has been well tolerated and reduced CAU signs and symptoms in phase III clinical trials [6]. However, after drug discontinuation, symptoms gradually recurred over a period of about 10 weeks. Furthermore, its high costs and limited availability represent a problem in most settings.

On the other hand, Hashimoto thyroiditis usually presents with euthyroidism or hypothyroidism, even though in some cases an initial hyperthyroid phase has been described, which usually does not require medical treatment, and resolves in a hypothyroidism, requiring treatment with levothyroxine. Surgery is only used seldomly, in some patients with goitrous disease and compressive symptoms [32]. However, in GD, once stable, patients can receive definitive therapy with surgery or radioiodine. In this case, the course of thyroid autoimmunity may be very different depending on the chosen treatment. Thus, complete removal of thyroid tissue by surgery with its antigenic components results in the disappearance of antibodies to all major thyroid antigens [28]. Accordingly, several studies show a better immunological response in surgical patients when compared with radioiodine [29].

As in our patient, 3 cases of immediate CAU remission in the context of AITD have been reported after thyroidectomy ( 2 Hashimoto's and one Graves') [4,30,31]. In 2 of these cases autoimmunity had become negative at 6 months (Hashimoto's) and 18 months follow-up (Graves'). In the third case, autoimmunity after surgery was not recorded, though. 6 other cases of urticaria remission after surgery have also been described in the context of PTC [13-15] ( $\bullet$ Table 1). Unfortunately, immunological data have not been reported in all of these PTC patients. On the other hand, one case of CAU 6 years after receiving radioiodine treatment for GD has been reported. In this patient, a concurrent increase of thyroid autoantibodies was detected along with the CAU [23].

Table 1 Case reports of CAU remission after thyroidectomy.

\begin{tabular}{|c|c|c|c|c|c|c|c|c|}
\hline $\begin{array}{l}\text { Case } \\
\text { Number }\end{array}$ & Author & Year & Age & Gender & Thyropathy & Autoantibodies titer & Follow-up & $\begin{array}{l}\text { Time of } \\
\text { follow-up }\end{array}$ \\
\hline 1 & Cailleba et al. & 1993 & not recorded & female & Graves' disease & not recorded & cured & not recorded \\
\hline 2 & Amoroso et al. & 1996 & 60 & female & thyroiditis & $\begin{array}{l}\text { Anti-Tg 1:40 Anti- } \\
\text { TPO > 1:25 } 600\end{array}$ & $\begin{array}{l}\text { cured Anti-Tg nega- } \\
\text { tive Anti-TPO 1:6400 }\end{array}$ & 18 months \\
\hline 3 & Raza et al. & 2004 & 29 & female & thyroiditis & $\begin{array}{l}\text { Anti-Tg } 3 \text { Anti-TPO }>70 \mathrm{IU} / \\
\mathrm{mL} \text { and } 3.0 \mathrm{IU} / \mathrm{mL}\end{array}$ & cured & 25 months \\
\hline 4 & Manganoni et al. & 2007 & 39 & female & TPC & negative & cured & 6 years \\
\hline 5 & Manganoni et al. & 2007 & 32 & female & TPC & negative & cured & 7 years \\
\hline 6 & Manganoni et al. & 2007 & 61 & female & TPC & not recorded & cured & 5 years \\
\hline 7 & Manganoni et al. & 2007 & 42 & female & TPC & negative & cured & not recorded \\
\hline 8 & Ozkaya et al. & 2011 & 25 & female & TPC & negative & cured & 6 months \\
\hline 9 & Kartal et al. & 2012 & 25 & male & TPC & $\begin{array}{l}\text { Anti-Tg } 300 \mathrm{IU} / \mathrm{ml} \text { Anti-TPO } \\
55 \mathrm{IU} / \mathrm{ml}\end{array}$ & cured & 9 months \\
\hline
\end{tabular}




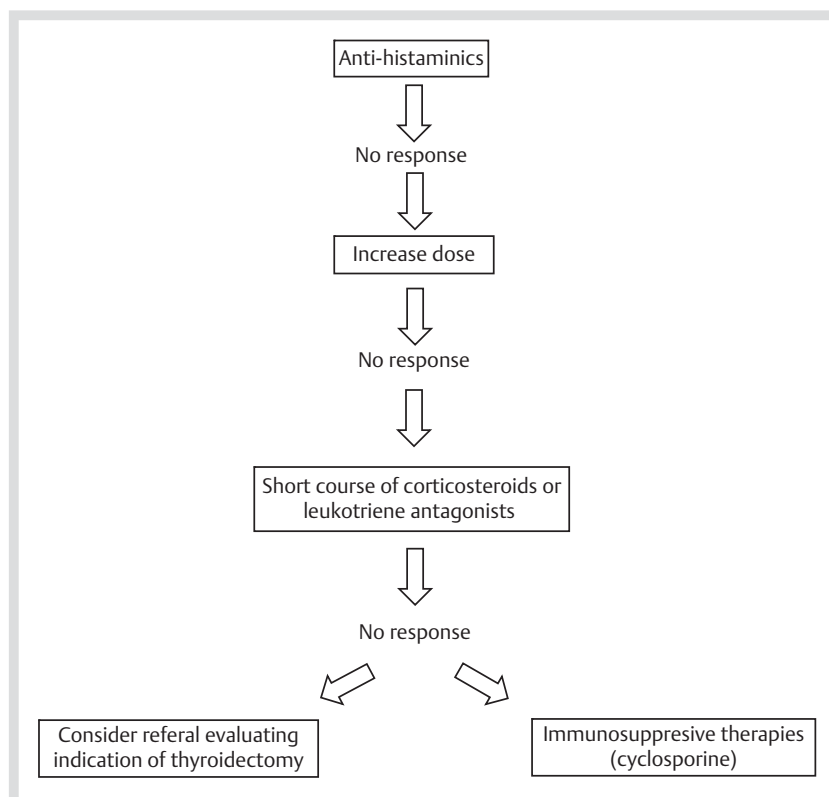

Fig. 3 Therapeutic algorithm for CAU in patients with AITD.

In conclusion, we describe a case of CAU associated to AITD that resolved immediately after thyroidectomy with a long lasting remission. Other cases of CAU remission after thyroidectomy have been reported in the literature. These cases together with epidemiological, clinical and experimental data suggest that these 2 entities are closely related and that thyroidectomy could benefit the course of CAU by removing thyroid antigens. Furthermore, thyroidectomy should be considered in patients with CAU and AITD when third and fourth-line treatment options are being needed for the treatment of the skin lesions ( $\bullet$ Fig. 3 ).

Conflict of interest: The authors declare no conflict of interest.

\section{References}

1 Leznoff A, Josse RG, Denburg J, Dolovich J. Association of chronic urticaria and angioedema with thyroid autoimmunity. Archives of Dermatology 1983; 119

2 Leznoff A, Sussman GL. Syndrome of idiopathic chronic urticaria and angioedema with thyroid autoimmunity: a study of 90 patients. Journal of Investigational Allergology and Clinical Immunology 1989; 84

3 Small P, Lerman S. Hyperthyroidism and polycythemia vera with chronic urticaria and angioedema. Annals of allergy 1981; 46

4 Cailleba A, Andre P, Thieblot P, Lauras H, Moinade S. Association rare d'une urticaire ET d'une maladie de Basedow. La Presse Médicale 1984; 13

5 Aamir IS, Tauheed S, Majeed F, Atif A. Serum antithyroid antibodies in female patients with chronic urticaria. Journal of the College of Physicians and Surgeons Pakistan 2008; 18: 498-501

6 Asero R, Tedeschi A, Cugno M. Treatment of Refractory Chronic Urticaria. American Journal of Clinical Dermatology 2013; 14: 481-488

7 Verneuil L, Leconte C, Ballet JJ, Coffin C, Laroche D, Izard JP, Reznik Y, Leroy $D$. Association between Chronic Urticaria and Thyroid Autoimmunity: A Prospective Study Involving 99 Patients. Dermatology 2004; 208: 98-103

8 Fernández Romero DS, Malbran A. Urticaria crónica con alteraciones de la función tiroidea y anticuerpos antiperoxidasa tiroidea. Medicina. (Buenos Aires) 2005; 65: 231-234

9 O'Donnell BF, Francis DM, Swana GT, Seed PT, Kobza Black A, Greaves $M W$. Thyroid autoimmunity in chronic urticaria. British Journal of Dermatology 2005; 153: 331-335

10 Cebeci F, Tankirut A, Topcu E, Onsun N, Kurtulmus N, Urasl AR. Association between chronic urticaria and thyroid autoimmunity. European Journal of Dermatology 2006; 16: 402-405
11 Feibelmann TCM, Torres Gonçalves F, Salomao Daud M, De Sousa Jorge A, Mantese SAO, Tannus Jorge P. Avaliação da Associação entre Doença Auto-Imune de Tireóide e Urticária Crônica Idiopática. Arquivos Brasileiros de Endocrinologia \& Metabologia 2007; 51/7: 1077-1083

12 Confino-Cohen R, Chodick G, Shalev V, Leshno M, Kimhi O, Goldberg A. Chronic urticaria and autoimmunity: Associations found in a large population study. Journal of allergy and clinical immunology 2012

13 Kartal O, Abdullah B, Ramazan E, Mustafa G, Zafer C, Osman S. Acute urticaria associated with thyroid papillary carcinoma: a case report. Annals of Dermatology 2012; 24

14 Ozkaya E, Elinç-Aslan MS, Yazici S. Aquagenic urticaria and syncope associated with occult papillary thyroid carcinoma and improvement after total thyroidectomy. Archives of Dermatology 2011; 147

15 Manganoni AM, Tucci G, Venturini M, Farisoglio C, Baronchelli C, Calzavara Pinton PG. Chronic Urticaria Associated With Thyroid Carcinoma: Report of 4 Cases. Journal of Investigational Allergology and Clinical Immunology 2007; 17: 192-195

16 Ferrer M, Kinet JP, Kaplan AP. Comparative studies of functional and binding assays for IgG anti-FceRI $\alpha$ ( $\alpha$-subunit) in chronic urticaria. Journal of Allergy and Clinical Immunology 1998; 101

17 Hide M, Francis DM, Grattan CEH, Hakimi J, Kochan JP, Greaves MW. Autoantibodies against the high-affinity IgE-receptor as a cause of histamine release in chronic urticarial. The New England Journal of Medicine 1993; 328

18 Fiebiger E, Maurer D, Holub H, Reiniger B, Hartmann G, Woisetschläger $M$, Kinet JP, Stingl J. Serum IgG antibodies directed against the $\alpha$ chain of FceRIa: a selective marker and pathogenic factor for a distinct subset of chronic urticarial patients? The Journal of Clinical Investigation 1995; 96: 2606-2612

19 Gruber BL, Baeza ML, Marchese MJ, Agnello V, Kaplan AP. Prevalence and functional role of anti-IgE autoantibodies in urticarial syndromes. The Journal of Investigative Dermatology 1988; 90

20 Kaplan AP. Chronic urticaria and angioedema. The New England Journal of Medicine 2002; 346

21 Bagnasco M, Minciullo PL, Schiavo M, Saraceno G, Gangemi S, Benvenga S. Urticária and Thyroid Autoimmunity. Thyroid 2011; 21

22 Brzoza Z, Grzeszczak W, Rogala B, Trautsolt W, Moczulski D. CTLA-4 polymorphism in the pathogenesis of chronic spontaneous autoreactive urticaria. Allergologia e immunopathologia 2013

23 Ramos-Prol A, Rubio-Almanza M, Campos-Alborg V, Febrer-Bosch I, Merino-Torres JF. Chronic autoimmune urticaria as a posible non endocrine manifestation of autoimmune polyglandular syndrome type II. Endocrinología y Nutrición 2011 04-006

24 Marone G, Spadaro G, Liccardo B, Rossi FW, D’Orio C, Detoraki A. Superallergens: a new mechanism of immunologic activation of human basophils and mast cells. Infl amm res 2006; 55 (Supplement 1): S25-S27

25 Wan Q Kita M, Flynn JC, Panos JC, Motte RW, Davies TF, Giraldo AA, David CS, Kong YM. Participation of Vb131 and Vb11 T Cells in Transfer Thyroiditis after Activation of Mouse Thyroglobulin-Primed T Cells by Superantigen Staphylococcal Enterotoxin A1. Cellular Immunology 2001; 213: 149-157

26 Papamichael KX, Papaioannou G, Karga H, Roussos A, Mantzaris GJ. Helicobacter pylori infection and endocrine disorders: is there a link? World Journal Gastroenterology 2009; 15: 2701-2707

27 Akeno N, Blackard JT, Tomer Y. HCV E2 protein binds directly to thyroid cells and induces IL-8 production: a new mechanism for HCV induced thyroid autoimmunity. Journal of Autoimmunology 2008; 31: 339-344

28 Chiovato L, Latrofa F, Braverman LE, Pacini F, Capezzone M, Masserini L, Grasso L, Pinchera A. Disappearance of humoral thyroid autoimmunity after complete removal of thyroid antigens. Annals of Internal Medicine 2003; 139 (5 Pt 1): 346-351

29 Laurberg P, Wallin G, Tallstedt L, Abraham-Nordling M, Lundell G, Torring 0 . TSH-receptor autoimmunity in Graves' disease after therapy with anti-thyroid drugs, surgery, or radioiodine: a 5-year prospective randomized study. European Journal of Endocrinology 2008; 158: 69-75

30 Raza SA, Salam Z, Blank RD, Jaume J, Drezner MK. Severe angioedema and urticaria related to thyroid antigenicity. Endocrine Practice 2004; 10

31 Amoroso A, Garzia P, Pasquarelli C, Sportelli G, Afeltra A. Hashimoto's thyroiditis associated with urticaria and angio-oedema: disappearance of cutaneous and mucosal manifestations after thyroidectomy. Journal of Clinical Pathology 1997; 50: 254-256

32 Hedayati $N$, McHenry $C R$. The clinical presentation and operative management of diffuse and nodular substernal thyroid disease. The American Journal of Surgery 68: 245-251 